\title{
Metodologias Ativas na formação profissional em saúde: uma revisão
}

\author{
Karla Taísa Pereira Colares \\ Mestranda em Ensino e Saúde pela Universidade Federal dos Vales do Jequitinhonha e Mucuri - UFVJM; \\ Especialização em Metodologia e Inovação do Ensino Superior pela Faculdade Vale do Gorutuba - FAVAG; \\ Especialização em Microbiologia Aplicada pelo Complexo Educacional Ibituruna e Graduada em Biomedicina \\ pela Faculdade de Saúde Ibituruna - FASI. Docente no curso de Enfermagem da FAVAG estudando e aplicando \\ metodologias. Responsável técnica no laboratório de Biologia na Universidade Federal dos Vales do \\ Jequitinhonha e Mucuri, Campus Janaúba. \\ $\triangle \underline{\text { karla.colares@ufvjm.edu.br }}$

\section{Wellington de Oliveira} \\ Doutor em Educação pela Universidade Federal de Minas Gerais UFMG, mestrado em Educação pela UFMG e \\ graduação em História - Licenciatura Plena também pela UFMG. Atualmente é Professor adjunto da \\ Universidade Federal dos Vales do Jequitinhonha e Mucuri - Campus JK; coordenador do Mestrado \\ Profissionalizante Ensino em Saúde- ENSA; orientador de dissertações de mestrado no referido mestrado e no \\ Mestrado Gestão em Educação, ambos na UFVJM. Tem experiência na área de Educação, com ênfase em \\ História da Educação, atuando principalmente nos seguintes temas: história - educação, educação e trabalho, \\ formação de professores-história, ensino história - livro didático e sociologia e educação. Desenvolve pesquisas \\ no campo de educação popular e saúde. \\ 凶elltha@terra.com.br
}

Recebido em 28 de agosto de 2018

Aceito em 25 de outubro de 2018

\section{Resumo:}

A formação profissional em saúde, historicamente, tem sido baseada em métodos de ensino tradicionais, fundamentados numa formação conteudista e tecnicista. No entanto, nas últimas décadas, tem se discutido a respeito da eficiência desse modelo em formar profissionais com espírito crítico reflexivo, aptos a resolver problemas na sua realidade, conforme previsto pelas Diretrizes Curriculares Nacionais (DCN's). Neste contexto, se abrem as discussões sobre o uso de metodologias ativas na formação profissional em saúde. 0 objetivo deste estudo é analisar a produção científica sobre o uso de metodologias ativas na formação profissional em saúde. Pretende se ainda, discorrer brevemente sobre a formação e atuação do docente da área de saúde. Trata-se de uma revisão narrativa realizada a partir da pesquisa bibliográfica em artigos científicos indexados nas bases de dados Scielo, e Capes Periódicos, livros, documentos públicos e outras publicações de cunho científico disponíveis on-line. A literatura tem se reportado às metodologias ativas como estratégia relevante no Ensino em Saúde, capaz de estimular no discente a autonomia, a reflexão, a criticidade e a capacidade de solucionar impasses, aproximando o conhecimento teórico e técnico da realidade. Apesar do crescente movimento para o uso dessas metodologias, evidencia-se uma predominância ao ensino tradicional. $\mathrm{O}$ uso das metodologias ativas constitui ainda um desafio, pois, requer a ruptura de paradigmas e revela uma ausência e/ ou deficiência na formação pedagógica dos docentes. Percebese ainda, uma escassez de estudos que abordem os aspectos avaliativos bem como, o nível de satisfação dos estudantes da saúde no âmbito das metodologias ativas.

Palavras-chave: Formação Profissional em Saúde, Metodologias ativas, Ensino em Saúde, Escola Nova. 


\title{
Active methodologies in health professional training: a review
}

\begin{abstract}
:
The professional training in health, historically, has been based on traditional teaching methods, based on a content and technical formation. However, in the last decades, it has been discussed about the efficiency of this model in training professionals with a reflexive critical spirit, able to solve problems in their reality, as provided by the National Curricular Guidelines (DCNs). In this context, discussions on the use of active methodologies in professional health training are open. The objective of this study is to analyze the scientific production on the use of active methodologies in professional training in health. It also intends to briefly discuss the training and performance of the health teacher. This is a narrative review based on the bibliographic research in scientific articles indexed in the Scielo, Capes Periódicos, books, public documents and other scientific publications available online. Literature has been reported to the active methodologies as a relevant strategy in Health Teaching, capable of stimulating in the student the autonomy, the reflection, the criticity, and the capacity to solve impasses, bringing the theoretical and technical knowledge of reality. Despite the growing movement towards the use of these methodologies, a predominance of traditional teaching is evident. The use of active methodologies is still a challenge, since it requires the breaking of paradigms and reveals an absence and / or deficiency in the pedagogical formation of teachers. There is also a shortage of studies that address the assessment aspects as well as the level of satisfaction of health students in the scope of active methodologies.
\end{abstract}

Keywords: Professional Training in Health, Active methodologies, Teaching in Health, New School.

\section{Metodologías Activas en la formación profesional en salud: una revisión}

\begin{abstract}
Resumen:
La formación profesional en salud, históricamente, ha sido basada en métodos de enseñanza tradicionales, fundamentados en una formación contudista y tecnicista. Sin embargo, en las últimas décadas, se ha discutido acerca de la eficiencia de este modelo en formar profesionales con espíritu crítico reflexivo, aptos para resolver problemas en su realidad, conforme a lo previsto por las Directrices Curriculares Nacionales (DCN's). En este contexto, se abren las discusiones sobre el uso de metodologías activas en la formación profesional en salud. El objetivo de este estudio es analizar la producción científica sobre el uso de metodologías activas en la formación profesional en salud. Se pretende, además, discurrir brevemente sobre la formación y actuación del docente del área de salud. Se trata de una revisión narrativa realizada a partir de la investigación bibliográfica en artículos científicos indexados en las bases de datos Scielo, y Capes Periódicos, libros, documentos públicos y otras publicaciones de cunho científico disponibles on-line. La literatura se ha reportado a las metodologías activas como estrategia relevante en la Enseñanza en Salud, capaz de estimular en el discente la autonomía, la reflexión, la criticidad, y la capacidad de solucionar impasses, aproximando el conocimiento teórico y técnico de la realidad. A pesar del creciente movimiento hacia el uso de esas metodologías, se evidencia un predominio a la enseñanza tradicional. El uso de las metodologías activas constituye aún un desafío, pues, requiere la ruptura de paradigmas y revela una ausencia y / o deficiencia en la formación pedagógica de los docentes. Se percibe además una escasez de estudios que aborden los aspectos evaluativos así como el nivel de satisfacción de los estudiantes de la salud en el ámbito de las metodologías activas.
\end{abstract}

Palabras clave: Formación Profesional en Salud, Metodologías activas, Enseñanza en Salud, Escuela Nueva. 


\section{INTRODUÇÃO}

A formação profissional em saúde, historicamente, tem sido baseada em métodos de ensino tradicionais, fundamentados numa formação conteudista e tecnicista. Sob esta perspectiva, o processo de ensino-aprendizagem se limita, muitas vezes, a um modelo fragmentado do saber no qual o docente assume um papel central de detentor e transmissor do conhecimento, enquanto o discente assume um papel passivo apenas retendo e reproduzindo aquilo que recebeu do docente (ROMAN, et al., 2017; MITRE et al., 2008).

Neste contexto, vários estudos têm discutido sobre o uso de metodologias ativas no processo de ensino aprendizagem, no âmbito da formação profissional em saúde (FINI, 2018; CALDARELLI, 2017; ROMAN, et al., 2017; SANTOS et al., 2017). As instituições de Ensino Superior têm sido pressionadas por mudanças no sentido de formar profissionais proativos, aptos a atuar na sociedade contemporânea e que sejam instrumentos de transformação em sua realidade.

A análise das Diretrizes Curriculares Nacionais (DCN's), dos cursos da área da saúde, corrobora esta ideia, uma vez que aponta para a necessidade de um ensino crítico-reflexivo e a da implementação de metodologias que estimulem o aluno a refletir sobre a realidade social e aprenda a aprender (BRASIL, 2001).

As metodologias ativas constituem uma estratégia de ensino-aprendizagem baseada na problematização com o objetivo de alcançar e motivar o discente, o qual diante de um problema, analisa, reflete e decide sobre determinada situação, apresentando envolvimento ativo no seu processo de formação (ARAUJO, 2015).

Considerando o perfil dos profissionais de saúde, delineado pelas DCN's faz se necessário refletir sobre o processo de formação destes profissionais, bem como, as metodologias envolvidas nesse processo, discutindo a utilização de novas técnicas de ensino aprendizagem. Diante do exposto, o objetivo deste estudo é analisar a produção científica sobre o uso de metodologias ativas na formação profissional em saúde. Pretende se ainda, discorrer brevemente sobre a formação e atuação do docente da área de saúde. 


\section{MÉTODO}

Trata-se de um estudo qualitativo de revisão narrativa. Segundo Rother (2007, p. 5) “os artigos de revisão narrativa são publicações amplas apropriadas para descrever e discutir o desenvolvimento ou o 'estado da arte' de um determinado assunto, sob ponto de vista teórico ou conceitual". São textos desenvolvidos a partir da análise da literatura científica na interpretação e análise crítica do autor, podendo contribuir no debate de determinadas temáticas, levantando questões, evidenciando novas ideias, subtemas e colaborando ainda, na aquisição e atualização do conhecimento em curto espaço de tempo (COSTA et al., 2015).

Para a elaboração deste estudo utilizou-se a pesquisa bibliográfica referente à temática abordada, em artigos científicos indexados nas bases de dados Scielo, Capes Periódicos; livros de pensadores da educação, documentos públicos e outras publicações de cunho científico disponíveis on-line.

No que concerne à busca de artigos, foram utilizados os seguintes descritores: metodologia ativa, ensino em saúde, problematização, PBL, competências, docência no ensino superior e revisão narrativa. Os artigos selecionados foram publicados no período entre 2005 e 2018. Adotou-se como critérios de inclusão: estudos na íntegra, publicados no período citado, no idioma português e que tratasse da temática proposta neste estudo. Foram excluídas publicações duplicadas, presentes em mais de uma base de dados assim como, aquelas que não apresentaram pertinência com a temática. A busca de dados ocorreu de julho a outubro de 2018.

Após a leitura exploratória do material obtido, foram selecionadas as informações referentes à proposta deste estudo, com a posterior análise e categorização pelos seguintes eixos temáticos: Formação Profissional em Saúde, Fundamentos das Metodologias Ativas e Metodologias ativas na Formação Profissional em Saúde. 


\section{DESENVOLVIMENTO}

\section{Formação Profissional em Saúde}

Historicamente a formação profissional em saúde tem sido fundamentada no uso de metodologias conservadoras, sob forte influência do mecanicismo de inspiração cartesiananewtoniana, fragmentado e reducionista. Neste modelo, nota-se uma fragmentação do conhecimento, por meio das subdivisões da universidade em centros e departamentos e dos cursos em períodos ou séries e em disciplinas estanques. Tal fato fortalece a dicotomia entre teoria e prática bem como, a dissociação entre o conhecimento, passivamente adquirido, e o contexto social do discente. Este modelo fragmentado dificulta a articulação entre diferentes conteúdos, dificultando a aprendizagem. (LIMA, 2017; ROMAN et al., 2017; SANTOS et al., 2017).

Nos últimos anos, no entanto, discussões têm sido levantadas a respeito da Educação em Saúde, no Ensino Superior, chamando a atenção para a necessidade da formação profissional em consonância com os princípios preconizados pelo SUS e capaz de atender às necessidades do atual contexto social (ROMAN et al., 2017; MELO, ALVES e LEMOS, 2014). Sob esta ótica, o Ministério da Saúde em diálogo com o Ministério da Educação tem direcionado esforços para integrar as políticas públicas aos serviços de saúde, bem como relacionar a prática na graduação com a assistência prestada à população. Dentre estes esforços podemos citar o Programa Nacional de Reorientação da Formação Profissional em Saúde (Pró-Saúde) e Programa de Educação pelo Trabalho (PET-Saúde).

O Pró-Saúde, lançado em 2005, visa à aproximação entre a formação da graduação e as necessidades da atenção básica, que no Brasil se traduzem pela Estratégia de Saúde da Família (ESF). Articulado ao Pró-Saúde, o PET-Saúde, lançado em editais anuais de 2008 a 2013, objetiva ampliar, promover, articular e apoiar ações e atividades de formação, voltadas às mudanças das graduações na saúde e a integração ensino-serviço-comunidade articuladas à educação permanente (BRASIL, 2008; BRASIL, 2009). De acordo com Vendruscolo, Silva e Silva (2017) esses programas têm em comum a proposta de integrar ensino-serviçocomunidade no processo de formação, evidenciando os cenários de prática como lócus singular para a reflexão sobre a real condição da produção de cuidados e a necessidade de transformação do atual modelo de atenção, centralizado no profissional e nas técnicas. 
Ressaltam que essa interação se pauta em um trabalho coletivo, pactuado e integrado entre docentes e discentes dos cursos de formação, trabalhadores, gestores e usuários dos serviços.

Em consonância com o acima exposto, a Lei de Diretrizes e Bases da Educação Nacional (LDBEN), no cenário da educação superior, define entre suas finalidades o desenvolvimento do espírito científico e do pensamento reflexivo; o estímulo ao conhecimento dos problemas do mundo atual, a prestação de serviços especializados à população no contexto regional e nacional, estabelecendo com ela uma relação de reciprocidade (BRASIL, 1996).

As DCN's dos cursos da área de saúde reiteram as premissas da LDBEN, dispondo sobre a importância de um processo formativo que viabilize o atendimento às demandas da sociedade, com destaque para as necessidades do SUS. As DCN's determinam que devam ser contemplados os elementos de fundamentação essencial em cada área do conhecimento, visando promover no estudante a competência do desenvolvimento intelectual e profissional autônomo e permanente. $\mathrm{O}$ estudante deverá estar apto a posicionar-se criticamente frente ao contexto sócio-político-econômico do país, atuando como agente de transformação e reconhecendo o papel da prática de profissional no contexto social (BRASIL, 2001; VIEIRA, et al., 2016).

No que tange ao desenvolvimento da autonomia e capacidade de aprender a aprender, ressalta-se que estas competências são fundamentais no profissional de saúde contemporâneo, uma vez que, o processo de formação acadêmica e/ou profissional não se encerra com a concessão do diploma de graduação. As necessidades dos serviços de saúde e das demandas sociais vão se modificando com o decorrer do tempo, assim, estes profissionais devem estar aptos a adequarem suas práticas a novos contextos.

As DCN's da área da saúde foram aprovadas entre 2001 e 2004, sendo de suma relevância, pois, definem o perfil acadêmico e profissional com competências, habilidades e conteúdos contemporâneos, bem como, a integração entre universidade, comunidade e serviço. A formação de recursos humanos para as profissões da área da saúde deve pautar-se no entendimento que saúde é um processo de trabalho coletivo do qual resulta, como produto, a prestação de cuidados à saúde e aptidão a transformar a realidade local, regional e nacional. As premissas das DCN's também pressionam por reformas curriculares nos cursos de graduação, com ampliação dos cenários de aprendizagem e desenvolvimento e aplicação 
de novas metodologias de ensino-aprendizagem em que o estudante se configure como o ator principal deste processo.

Diante deste contexto, as Instituições de Ensino Superior (IES) têm sido motivadas a refletirem e mudarem suas práticas pedagógicas, no intuito de se aproximarem da realidade social e de motivarem seus corpos docente e discente a desenvolverem um novo modelo de construção de conhecimento que permita atender aos novos perfis delineados para seus profissionais. Sob esta perspectiva, surgem diversos debates sobre o uso de metodologias ativas como estratégia para o desenvolvimento de competências e habilidades necessárias aos profissionais de saúde (REUL et al., 2016).

Ao refletirmos sobre a Formação Profissional em Saúde os termos competências e habilidades são recorrentes. Quanto ao significado do termo competência, de acordo com Vieira et al., (2016), refere-se ao saber fazer com qualidade. Perrenoud (1999) descreve este termo como a faculdade de mobilizar um conjunto de recursos cognitivos (saberes, capacidades, informações e habilidades) a fim de solucionar com pertinência e eficácia uma série de situações. Estão ligadas a contextos culturais, profissionais e condições sociais. Já habilidade é descrita pelo autor como algo menos amplo que as competências, assim, a competência estaria constituída por várias habilidades. Entretanto, uma habilidade não "pertence" a determinada competência, uma vez que uma mesma habilidade pode contribuir para competências diferentes. Por meio das ações e operações, as habilidades aperfeiçoam-se e articulam-se, possibilitando nova reorganização das competências.

Para o desenvolvimento e exercício das competências e habilidades inerentes ao exercício profissional em saúde, é necessário que o Ensino em Saúde lance mão de metodologias inovadoras que possibilitem a interação entre o estudante e os diferentes cenários em que estes profissionais estarão inseridos, viabilizando a contextualização e aplicabilidade dos conhecimentos. A esse respeito, as metodologias ativas oportunizam que o aluno desenvolva um espírito critico e reflexivo sobre a realidade e que seja capaz de mobilizar seus conhecimentos de forma ativa, sabendo elencar meios para solucionar problemas. 


\section{Fundamentos das Metodologias Ativas}

A educação, ao longo da história, tem passado por relevantes processos de mudança, através dos quais se estabeleceu uma nova dinâmica na relação entre educador e educando. Neste novo cenário da sociedade contemporânea, o educando deve assumir o seu papel na construção do conhecimento e o educador atuar como facilitador desse conhecimento (FARIAS, MARTIN e CRISTO, 2015). No entanto, é importante salientar, que a educação como hoje existe, é resultado de experiências ao longo da história, das diferentes demandas da sociedade, pois, através da experiência, é possível se reconstruir valores, desenvolver novos critérios de estrutura da sociedade e assim, acrescentar novos valores (BEVILAQUA, 2014).

Tendo em vista que o aprofundamento deste estudo não reside nos fatos históricos, trataremos nesta secção apenas de alguns aspectos da transição entre o paradigma do ensino tradicional e o paradigma escolanovista, considerando este último como um dos pontos de partida para as metodologias ativas.

No Brasil, a metodologia ativa surge, substancialmente, do Movimento Escola Ativa ou escolanovismo e pressupõe a aprendizagem, através da hegemonia do aluno sobre o professor (ARAUJO, 2015). Ao contrário da tendência liberal tradicional, a Escola Ativa leva em consideração as experiências e conhecimentos adquiridos fora do espaço escolar e parte deles para a construção do processo de aprendizagem. Utiliza das experiências prévias do discente para a construção de saberes dotados de significado e aplicáveis à sua realidade (QUEIROZ e MOITA, 2007).

Por educação nova entendemos a corrente que trata de mudar o rumo da educação tradicional, intelectualista e livresca, dando-lhe sentido vivo e ativo. Por isso se deu também a esse movimento o nome de "escola ativa"" (LUZURIAGA, 1980, p. 227).

O Manifesto dos Pioneiros da Educação Nova, lançado em 1932, constitui um marco na educação brasileira, condensando a insatisfação e crítica da jovem intelectualidade brasileira ao sistema educacional. Os signatários do Manifesto inspiraram-se nas ideias filosóficas e pedagógicas mais avançadas da Europa e Estados Unidos e nas concepções de John Dewey e Durkheim. Elaborado no governo de Getúlio Vargas, o movimento contou com a participação de pensadores da educação tais como, Fernando de Azevedo, Anísio Teixeira e Lourenço Filho 
(BEVILAQUA, 2014). Há que se destacar que o movimento escolanovista aconteceu em um momento em que o Brasil passava por uma série de transformações políticas, econômicas e sociais.

O manifesto apresentou-se como um instrumento político que objetivou traçar uma nova política educacional em defesa da escola para todos e a democratização do acesso á educação. Criticava o modelo educacional vigente e defendia um ideário de ensino mais instigador. Segundo Saviani (2004) o Manifesto pode ser considerado um legado que nos foi deixado pelo século XX.

Segundo o educador norte-americano John Dewey, primeiro a formular o novo ideal pedagógico, a Escola Nova deve se dar pela ação e não pela instrução - learning by doing - ou o aprender fazendo. Ele defendia que a escola deveria ser um ambiente de experiências instigadoras em que o professor deve ser o incentivador. Sob esta perspectiva, a escola deve propiciar um espaço de descobertas em que o conhecimento não seja, exclusivamente, apresentado pelo docente, mas sim que o aluno também busque e construa seu aprendizado. Pressupõe um processo de ensino aprendizagem a partir de experiências concretas, ativas e produtivas de cada discente (CARON, SOUZA E SOUZA; 2016).

Dewey defendia o ensino através de uma metodologia problematizadora em que os conteúdos fossem apresentados em forma de questões ou problemas, assim, o discente atua ativamente na formulação de conceitos e na resolução de problemas. Sob esta ótica, apresenta uma proposta de educação centrada no desenvolvimento do raciocínio, do espírito crítico reflexivo e de competências que tornem o discente apto a resolver situações cotidianas. Desse modo, a educação propiciaria um aperfeiçoamento das relações sociais e uma aproximação entre escola e sociedade (CARON, SOUZA E SOUZA, 2016).

Para Simon et al., (2014) a concepção pedagógica de Dewey compreende a educação como práxis transformadora a qual objetiva a formação de cidadãos competentes, criativos e capazes de gerenciar sua liberdade em uma sociedade democrática. Consideram por esta razão, a pedagogia de Dewey como a expressão da democracia na educação.

Podemos perceber então, elementos em comum entre ideal pedagógico de Dewey e a concepção pedagógica progressista de Paulo Freire "Educação como prática da liberdade". Freire preconiza para a educação contemporânea o discente capaz autogerenciar e autogovernar seu processo de formação, em que problematização, diálogo, liberdade e 
conscientização são elementos-chave. Para Freire a curiosidade do professor e aluno, em ação, se encontra na base do ensinar - aprender (ADADA, 2017; SILVA, ASSIS, GENTILE, 2005).

Paulo Freire denúncia a educação bancária e, num segundo momento, anuncia uma pedagogia libertadora freireana: problematizadora e conscientizadora. Para o autor a concepção de educação bancária desconsidera o diálogo, à medida que na prática pedagógica prevalecem poucas palavras, sendo "o educador é o que diz a palavra; os educandos, os que a escutam docilmente; o educador é o que disciplina; os educandos, os disciplinados" (Freire, 2005, p. 68). Desse modo, entendemos que o professor irá “depositar” (daí a ideia de "bancária") os conteúdos nas cabeças dos educandos, como se fossem recipientes vazios a serem preenchidos.

Podemos perceber, pois, que assim como a história, as concepções pedagógicas também são dinâmicas, e por esta razão outros conceitos pedagógicos se apresentaram como alternativas à Escola Nova, à pedagogia de Paulo Freire bem como, de outros filósofos da educação, não podendo se negar as contribuições de cada um.

\section{Metodologias ativas na Formação Profissional em Saúde}

As metodologias ativas de ensino aprendizagem constituem estratégias metodológicas centradas na figura do aluno. Nesse caminho, o estudante é o protagonista do processo, enquanto o professor irá atuar como facilitador ou orientador para que o estudante pesquise, reflita e decida por ele mesmo, diante de situações problema, atingindo os objetivos de aprendizagem propostos (ARAUJO, 2015).

Santos et al., (2017) reiteram este conceito ao definir metodologias ativas como processos interativos de conhecimento permeados pela análise, estudos, pesquisas e decisões tanto em nível individual quanto coletivo, desenvolvendo o processo de aprender a partir de experiências reais ou simuladas, visando solucionar, com êxito, desafios advindos da prática profissional e social em diferentes contextos.

Paulo Freire (1999) defensor das metodologias ativas, afirma que na educação de adultos, o que impulsiona a aprendizagem é a superação de desafios, a resolução de problemas 
e a construção do conhecimento novo a partir de conhecimentos e experiências prévias dos indivíduos.

Para Diesel, Baldez e Martins (2017) o que distingue a metodologia ativa da metodologia tradicional é essencialmente, o papel ativo que o aluno assume, deixando de ser um mero receptor de conhecimentos, antes transmitidos, exclusivamente, pelo professor. Para tanto, o estudante pesquisa, ouve, pergunta, reflete, discute e a partir dessa dinâmica constrói o conhecimento. Desse modo, ele estará exercitando diferentes habilidades tais como, refletir, observar, comparar, inferir, dentre outras, e não apenas ouvindo aulas expositivas, muitas vezes mais monologadas que dialogadas.

Diante dos conceitos supracitados, percebe-se que o elemento chave das metodologias inovadoras reside em estimular a postura ativa do estudante, o qual deverá comprometer-se com seu aprendizado. Além disso, tais metodologias devem promover uma aproximação crítica do aluno com a realidade; pressupondo a reflexão diante de situações problema e a geração de conhecimento que o torne apto à resolução de impasses no seu cotidiano. É necessário que seja estimulado no estudante a curiosidade, o desafio e a criatividade, concebendo significado e aplicabilidade ao conhecimento gerado.

Ao tratarmos sobre metodologia ativa, não podemos deixar de pontuar o seu papel sobre o desenvolvimento da autonomia do estudante. A esse respeito, Berbel (2011) afirma que tal metodologia tem a potencialidade de despertá-la, à medida que os estudantes se inserem na teorização, trazendo novos elementos, ainda desconsiderados nas aulas ou sob a própria perspectiva do docente. Quando acatadas e analisadas as contribuições dos alunos, valorizando-as, são estimulados os sentimentos de engajamento, percepção de competência e de pertencimento, além da persistência nos estudos, entre outras. Santos et al., (2017) também reconhecem o papel dessas metodologias no despertar da curiosidade e na promoção da autonomia e mencionam que trabalhos anteriores relataram melhorias no que se refere a motivação e aprendizagem, na formação de profissionais da saúde, quando comparadas às metodologias tradicionais. Roman et al., (2017) também relatam aspectos positivos com relação ao uso de metodologias ativas no Ensino em Saúde, apontando suas contribuições em dar significância ao conhecimento e no estreitamento das relações entre discente e docentes, o que se reflete como facilitadores de aprendizagem. 
Embora haja nas últimas décadas, um forte movimento no sentido de se estimular o uso de metodologias ativas, é válido ressaltar, que estas não anulam ou excluem a metodologia tradicional no processo de ensino aprendizagem, podem, inclusive, ser utilizadas de forma combinada.

Fini (2018) afirma que um dos grandes desafios do Ensino Superior, na atualidade, é formar profissionais aptos a enfrentar mudanças, seja no campo tecnológico, científico e social, uma vez que estes estão em constante mudança e exigem, por conseguinte, capacidade contínua de adaptação e aperfeiçoamento das novas formas de trabalho e vida. Diante disso, percebe-se que a formação profissional deve estar pautada numa metodologia libertadora e não em métodos restritos a memorização de conteúdos. A autora salienta: “informação não é conhecimento, e que memória não é inteligência; e principalmente, que tecnologia não é pedagogia" (p.176).

Perante o atual contexto de uma sociedade globalizada e em constante transformação, o conhecimento representa recurso importante para os seres humanos, residindo na educação a expectativa e a responsabilidade de formar e educar cidadãos aptos a atender as necessidades do ser social. A formação profissional em saúde representa uma das mais importantes fontes de possibilidade de implantação de um modelo contra hegemônico de atenção e consolidação do Sistema Único de Saúde (SUS), em termos de princípios e diretrizes (CARVALHO, 2016).

Dentre outras competências e habilidades específicas de cada profissão da saúde, o Conselho Nacional de Saúde define, em linhas gerais, que o profissional deverá estar apto à resolução de problemas de saúde, tanto em nível individual como coletivo; a tomar decisões apropriadas; ao exercício da liderança, da administração e do gerenciamento. Neste sentido, as metodologias ativas podem ser compreendidas como um modelo de formação profissional que viabiliza a formação de um profissional com um perfil mais condizente com os princípios e necessidades da atual política de saúde (BRASIL, 2001; MESQUITA, MENESES E RAMOS, 2016).

De acordo com Ferreira (2015) este perfil formativo assume novos aspectos a serem contemplados, o que é fomentado, por exemplo, pelas Diretrizes Curriculares Nacionais dos Cursos de Graduação em Enfermagem que problematizam e promovem a apreciação e ajustamento dos projetos políticos pedagógicos das instituições de ensino, com finalidade de atender novas perspectivas que preveem a sustentação de profissionais capazes de trabalhar 
sob a perspectiva da multidisciplinaridade, não especificamente para o agravo em saúde, mas dirigido às demandas sociais.

Repensar a formação presume fortalecer o movimento que envolve propostas que vão desde uma reforma curricular, com consequentes modificações dos projetos pedagógicos de cursos, até um plano da inovação de uma disciplina ou conteúdo curricular, uma vez que ambos podem contribuir para a transformação do processo de ensino aprendizagem na Saúde (CARVALHO, 2016).

As metodologias ativas no Ensino em Saúde vêm sendo desenvolvidas sob diferentes abordagens, a exemplo, menciona-se:

- Aprendizagem Baseada em Problemas ou problem -based- learning (BPL) - Neste método são preparadas situações, ou seja, temas de estudo que o aluno deverá saber e dominar, sendo determinados previamente quais conhecimentos o aluno deverá possuir para cada uma delas. Cada tema é transformado em um problema para ser discutido em pequenos grupos, visando o desenvolvimento do raciocínio crítico, habilidades de comunicação e o entendimento da necessidade da aprendizagem continuada (FUJITA, et al., 2016; PRADO et al., 2012).

- Teoria da Problematização utilizando o Arco de Mangarez - O método desenvolvido por Charles Maguerez e adaptado por Bordenave é constituído das seguintes etapas: observação da realidade, levantamento de pontos-chave, teorização, hipóteses de solução e aplicação na realidade. Nesta técnica o caminho a ser percorrido pelo discente parte da situação da realidade social observada, que provoca questionamento, a partir do qual se desenha o quadro conceitual que permite uma análise teórica do problema. Coletam-se dados relevantes, formulamse hipóteses norteadoras e chega-se a uma síntese ou solução, que envolve a transformação da realidade (FUJITA, et al., 2016).

- Aprendizagem baseada em equipes (ABE), também conhecida como team-based-learning (TBL) - No TBL o foco da atividade é introduzir conceitos relacionados a qualquer área de conhecimento e estimular o trabalho em equipe no desenvolvimento das tarefas. Essa metodologia requer planejamento minucioso e atuação dos estudantes acerca das leituras ou exercícios solicitados, 
previamente, pelo docente. Pode se sintetizar seu percurso metodológico em três etapas: A primeira consiste na preparação individual dos estudantes (pré-classe); a segunda etapa refere-se à avaliação da garantia do preparo, realizada através da aplicação de um teste contendo de 10 a 20 questões de múltipla escolha. 0 teste deve ser feito primeiramente, de maneira individual, e posteriormente, em grupos, onde eles deverão negociar opiniões e pontos de vista a fim de escolher apenas uma resposta. A última etapa trata-se da aplicação dos conhecimentos (conceitos) adquiridos por meio da resolução de situações problema (casosclínicos, por exemplo) nas equipes; deve ocupar a maior parte da carga horária (BOLLELA, et al., 2014).

Além das metodologias ativas acima descritas, existem diversas outras, aplicáveis a situações distintas, em pequenos ou grandes grupos. Dentre elas, pode-se citar Espiral Construtivista, Aprendizagem Baseada em Projetos, Instrução por Pares, Sala de Aula Invertida, Simulação entre outras (LIMA, 2017).

Ao analisarmos a literatura consultada, no que concerne a utilização dessas metodologias, percebe-se uma maior abundância de publicações, especialmente, do PBL e da Problematização, nos cursos da saúde. Ressalta-se que o BPL remonta ao século XX, tendo surgido como um movimento de reação aos currículos das escolas médicas sob a forte influência do modelo flexneriano, que privilegiava o modelo biomédico e o ensino centrado no hospital, desde então seu uso tem se difundido de modo crescente nos cursos da saúde (CAVALCANTE et al., 2018).

Mas de que maneira essas metodologias ativas contribuem com a aprendizagem? As reflexões e discussões sobre as situações-problema a que são expostos, desencadeia no estudante a busca de fatores explicativos e a suposição de soluções para o problema. Desta forma, problematizar significa ser capaz de responder ao conflito intrínseco que o problema traz. Os conteúdos são construídos pelo estudante que precisa reorganizar o material, adaptando-o à sua estrutura cognitiva prévia, para descobrir relações, leis ou conceitos que precisará assimilar; retirando da realidade elementos que conferem significado em direção à aprendizagem (OLIVEIRA-BARRETO et al., 2017).

Sob a perspectiva da prática docente, percebe-se como essencial que o professor conheça os mais variados métodos, suas funções, objetivos e formas de aplicação, de modo 
que possa combinar estratégias, objetivando manter o estudante ativo no processo. É importante compreender o papel do professor como um mediador, e que o processo de ensino aprendizagem deve acontecer em uma via de mão dupla, na qual docente e discente construam juntos o conhecimento (CARVALHO, 2016).

Carvalho (2016, p. 1333) salienta, no entanto, que "não basta apenas definir as técnicas e os instrumentos, mas, antes de tudo, deve-se realizar um planejamento crítico e consciente do processo de ensino-aprendizagem". Este planejamento crítico, reflexivo e de natureza coletiva, associado ao uso de estratégias inovadoras propicia ao docente mediar um processo de formação de profissionais capacitados e conscientes para transformar a realidade que os circunda.

Sobral e Campos (2012) corroboram essa ideia e acrescentam ser necessário que o docente conheça a concepção pedagógica adotada para aplicar os procedimentos adequados à aprendizagem. Os autores afirmam ainda que os novos métodos de ensino constituem um desafio, pois exige a ruptura do paradigma de um ensino centrado na figura do docente. Cabe mencionar, que a ruptura desse paradigma requer uma mudança no olhar sobre o processo do ensinar e aprender tanto por parte dos docentes quanto dos discentes.

Ao discutirmos a respeito do uso de metodologias ativas na formação profissional em saúde, indubitavelmente, não poderíamos deixar de refletir sobre a formação e desenvolvimento de docentes para atuarem na área da saúde. Trata-se de um tema atual o qual aborda aspectos referentes à prática pedagógica, estrutura curricular e sua formação didática, haja vista sua importância para a formação de profissionais aptos a atender e contribuir com a sociedade num contexto de frequentes mudanças (FELÍCIO et al., 2017)

Do ponto de vista da formação, evidencia-se a necessidade da ruptura de um modelo de ensino fragmentado e tecnicista, tendo em vista que a atuação dos profissionais da saúde não se restringe somente à assistência, engloba também a pesquisa, a gerência e a educação. A atuação na educação, assim como nas demais áreas, requer preparo uma vez que a função do professor não se define pelo simples domínio de conteúdos, mas pela utilização e mobilização desses saberes e em como fazer com que esse conteúdo possa ser ensinado e aprendido (TREVISO e COSTA, 2017).

Neste sentido Felicio e colaboradores (2018) afirmam que deve haver desde a formação, uma integração entre o ensino, o serviço que se oferece e a comunidade 
contemplada por esses serviços. Os autores salientam que aquilo que foi suscitado para esse profissional na sua graduação, irá orientar sua prática pedagógica, evidenciando todas as fortalezas e fragilidades da sua formação.

Na maioria das vezes, a docência na área da saúde é pautada na concepção de que o conhecimento técnico-científico é o bastante para atuarem como formadores de novos profissionais (COSTA, 2010). Por outro lado, a LDBEN apresenta como conceito de docência a formação específica articulada com a prática em sala de aula e diz, em seu Art. 66, que a preparação para o exercício do magistério superior deverá ocorrer em nível de pósgraduação, prioritariamente em programas de mestrado e doutorado. A esse respeito ressalta-se a importância dos programas stricto sensu como forma de capacitação pedagógica para o Ensino em Saúde.

Costa (2010) discute sobre a importância da capacitação pedagógica para a docência no ensino superior, assim como, a percepção de que além das competências específicas para exercer a profissão, aquelas mais restritas ás técnicas, existem também as competências relacionadas especificamente à docência universitária tais como: domínio de uma área do conhecimento, o conhecimento pedagógico e o exercício da dimensão política do ensino superior. $\mathrm{O}$ autor enfatiza que é sob o alicerce do docente que devem ser instituídas as mudanças necessárias à formação de profissionais da área da saúde, reconhece a relevância da necessidade de formação pedagógica e a necessidade de mudanças na prática docente em saúde com a formação do professor reflexivo. Assim, a capacitação docente deve compreendida como processo complexo e contínuo de preparação teórica, técnica e pedagógica.

\section{CONSIDERAÇÕES FINAIS}

O modelo educacional e as metodologias de ensino resultam do contexto sócio histórico e são, portanto, dinâmicos. Assim, é fundamental que se incorpore metodologias inovadoras no Ensino em Saúde, a fim de promover a formação de um profissional com o perfil delineado pela LDBEN, pelas DCN's e especialmente pelas demandas do SUS e da sociedade contemporânea. 
Neste sentido, o modelo de ensino tradicional, adotado na maioria dos cursos da área da saúde, tem sido amplamente questionado e a utilização de metodologias ativas tem sido tema atual. A literatura aponta que para se formar um profissional de saúde com espírito crítico reflexivo, apto a solucionar impasses no seu ambiente profissional e na sociedade, há a necessidade de um processo de formação que vá além do ensino conteudista e tecnicista. É necessário um processo formativo instigante que estimule a reflexão, a criatividade, a criticidade, a autonomia e a responsabilidade com a aprendizagem continuada, o que vai ao encontro das propostas das metodologias ativas. No entanto, o uso dessas metodologias constitui ainda, um desafio para maior parte dos docentes da saúde, uma vez que, requer uma mudança de paradigmas e revela uma ausência e/ ou deficiência na formação pedagógica desses docentes. È importante ressaltar, que o uso de metodologias inovadoras não anula ou exclui a metodologia tradicional, ambas podem, inclusive, ser combinadas com êxito no processo de ensino aprendizagem.

Apesar de um crescente movimento para uso das metodologias ativas na formação profissional em saúde, evidencia-se a partir da literatura consultada, que ainda há uma predominância ao ensino tradicional. Outros aspectos relevantes são que embora tenha havido um incremento de publicações científicas sobre esta temática, percebe-se uma escassez de estudos que abordem os aspectos avaliativos bem como, o nível de satisfação dos estudantes da saúde no âmbito das metodologias ativas.

\section{REFERÊNCIAS:}

ADADA, F. Estudo sobre a percepção do discente sobre as metodologias ativas na Educação Superior. 2017. 130f. Dissertação (Mestrado) - Programa de Pós-Graduação em Educação - Universidade Estadual do Oeste do Paraná, Campus Cascavel. Acesso em: <http://tede.unioeste.br/handle/tede/3340>. Acesso em: 16 de outubro de 2018.

ARAUJO, J. C. S. Fundamentos da metodologia de ensino ativa (1890-1931). 37ª Reunião Nacional da ANPEd 04 a 08 de outubro de 2015, UFSC - Florianópolis. Disponível em <http://www.anped.org.br/sites/default/files/trabalho-gt02-4216.pdf>. Acesso em 27 de julho de 2018.

BERBEL, N. A. N. As metodologias ativas e a promoção da autonomia de estudantes. Semina: Ciências Sociais e Humanas, Londrina, v. 32, n. 1, p. 25-40, jan./jun. 2011. <http://www.proiac.uff.br/sites/default/files/documentos/berbel_2011.pdf>. Acesso em 20 de julho de 2018.

BEVILAQUA, A. P. John Dewey e a Escola Nova no Brasil. Ciência \& Luta de Classes Digital, Ano I, Vol.1 N¹, 2014. Disponível em <https://ceppes.org.br/revista/edicoes-anteriores/edicao-agosto-de-2014-n-1-v1/bevilaqua-john-dewey-e-a-escola-nova-no-brasil/view>. Acesso em 27 de julho de 2018. 
BOLLELA,V. R; SENGER, M. H; TOURINHO, F. S. V; AMARAL, E. Aprendizagem baseada em equipes: em baseada em equipes: em baseada em equipes: da teoria à prática da teoria à prática. Revista de Medicina, Ribeirão Preto, v. 47, n. 3, p. 293-300, 2014. Disponível em: 〈http://www.revistas.usp.br/rmrp/article/view/86618/89548>. Acesso em: Acesso em: 19 de outubro de 2018.

BRASIL. Lei no 9.394 de 20 de dezembro de 1996. Estabelece as diretrizes da Educação Nacional. Diário Oficial da União 1996; 23 dez. Disponível em http://www.planalto.gov.br/CCIVIL_03/Leis/L9394.htm. Acesso em 27 de julho de 2018.

BRASIL. MINISTÉRIO DA EDUCAÇÃO. CONSELHO NACIONAL DE EDUCAÇÃO. Diretrizes Curriculares Nacionais do Curso de Graduação em Enfermagem. Resolução no 3 de 7 de novembro de 2001. Disponível em http://portal.mec.gov.br/cne/arquivos/pdf/CES03.pdf. Acesso em 25 de julho de 2018.

BRASIL. MINISTÉRIO DA SAÚDE. MINISTÉRIO DA EDUCAÇÃO. Portaria Interministerial MS/MEC no 1.802/2008. Institui o Programa de Educação pelo Trabalho para a Saúde - PET - Saúde. Ministério da Saúde, Ministério da $\quad$ Educação. $\quad$ Brasília: 2008.2 Disponível em: $<$ http://bvsms.saude.gov.br/bvs/saudelegis/gm/2008/pri1802_26_08_2008.html >. Acesso em 17 de outubro de 2018.

BRASIL. MINISTÉRIO DA SAÚDE. MINISTÉRIO DA EDUCAÇÃO. Programa Nacional de Reorientação da Formação Profissional em Saúde - Pró-Saúde: objetivos, implementação e desenvolvimento potencial. Ministério da Saúde, Ministério da Educação. Brasília: 2009. Disponível em: $<$ http://bvsms.saude.gov.br/bvs/publicacoes/programa_nacional_reorientacao_profissional_saude.pdf>.

Acesso em 17 de outubro de 2018.

CALDARELLI, P. G. A importância da utilização de práticas de metodologias ativas de aprendizagem na formação superior de profissionais da saúde. Revista Sustinere, Rio de Janeiro, v. 5, n. 1, p. 175-178, jan-jun. 2017. Disponível em: http://www.e-publicacoes.uerj.br/index.php/sustinere/article/view/26308. Acesso em 14 de outubro de 2018.

CARON, D; SOUZA, F. V.C; SOUZA, C. R. M. John Dewey e Paulo Freire: uma análise sobre a educação e democracia. Cadernos da Fucamp, v. 15, n. 22, p. 100-107/2016. Disponível em <http://www.fucamp.edu.br/editora/index.php/cadernos/article/viewFile/640/492> Acesso em 29 de julho de 2018.

CARVALHO, A. C. O; SOARES, J. R; MAIA, E. R; MACHADO, M. F. A. S; LOPES, M. S. V; SAMPAIO, K. J. A. J. O planejar docente: relato sobre uso de métodos ativos no ensino de enfermagem. Revista de Enfermagem da UFPE online, Recife, v. 10, n. 4, p.1332-8, abr. 2016. Disponível em <https://periodicos.ufpe.br/revistas/revistaenfermagem/article/download/11121/12603> Acesso em 31 de julho de 2018.

CAVALCANTE, A. N; LIRA, G. V; CAVALCANTE NETO, P.G; LIRA, R. C. M. Análise da Produção Bibliográfica sobre Problem-Based Learning (PBL) em Quatro Periódicos Selecionados. Revista Brasileira de Educação Médica, Brasília, v. 42, n. 1, p. 15-26, Jan. 2018. Disponível em: $<$ http://www.scielo.br/scielo.php?script=sci_arttext\&pid=S0100-55022018000100015\&lng=en\&nrm=iso>. Acesso em: 19 de outubro de 2018.

CoSTA, N. M. S. C. Formação pedagógica de professores de medicina. Revista Latino-Americana de Enfermagem, Ribeirão Preto, $\quad$ v. 18, n. 1, p. 102-108, Fev. 2010. Disponível em $<$ https://www.revistas.usp.br/rlae/article/view/4126/0>. Acesso em 20 de julho de 2018.

COSTA, P. H. A; MOTA, D. C. B; PAIVA, F. S; RONZANI, T. M. Unravelling the skein of care networks on drugs: a narrative review of the literature. Ciência \& Saúde Coletiva [Internet], v. 20, n. 2, p. 395-406, 2015. Disponível em: <http://www.scielo.br/scielo.php?script=sci_arttext\&pid=S1413-81232015000200395\&lng=en>. Acesso em: 15 de outubro de 2018.

DIESEL, A; BALDEZ, A. L. S; MARTINS, S. N. Os princípios das metodologias ativas de ensino: uma abordagem teórica. Revista Thema, Lajeado, v. 14, n.1, p. 268-288, 2017. Disponível em: < 
http://revistathema.ifsul.edu.br/index.php/thema/article/viewFile/404/295>. Acesso em: 17 de outubro de 2018.

FARIAS, P. A. M; MARTIN, A, L. A. R; CRISTO, C. S. Aprendizagem Ativa na Educação em Saúde: Percurso Histórico e Aplicações. Revista Brasileira de Educação Médica, Rio de Janeiro, v. 39, n. 1, p. 143150, Mar. 2015. Disponível em: <http://www.scielo.br/scielo.php?script=sci_arttext\&pid=S010055022015000100143\&lng=en\&nrm=iso>. Acesso em: 19 de outubro de 2018.

FELÍCIO, L. M; NETO, L. T. R; BARBOSA, R. L. C; DUMMAR, J. P. Formação e Prática Pedagógica para o Ensino na Saúde na Perspectiva dos Professores de uma Instituição de Ensino Superior em Fortaleza. Revista FSA, Teresina, v. 14, n. 4, art. 5, p. 89-99, jul./ago. 2017. Disponível em: $<$ http://www4.fsanet.com.br/revista/index.php/fsa/article/view/1391>. Acesso em: 18 de outubro de 2018.

FERREIRA, R. G. S. A educação permanente na formação contínua dos profissionais de enfermagem. Revista Sustinere, Rio de Janeiro, v. 3, n. 2, p. 128-142, jul-dez, 2015. Disponível em: < http://www.epublicacoes.uerj.br/index.php/sustinere/article/view/18127>. Acesso em: 17 de outubro de 2018.

FINI, M. I. Inovações no ensino Superior metodologias inovadoras de aprendizagem e suas relações com o mundo do trabalho: desafios para a transformação de uma cultura. Revista Sustinere, Rio de Janeiro, v. 19, n. 1, p. 176183, jan-abr 2018. Disponível em: <http://www.spell.org.br/documentos/ver/48840/inovacoes-no-ensinosuperior--metodologias-inovadoras-de-aprendizagem-e-suas-relacoes-com-o-mundo-do-trabalho--desafiospara-a-transformacao-de-uma-cultura>. Acesso em: 14 de outubro de 2018.

FREIRE, P. Pedagogia da autonomia: saberes necessários à prática educativa. 11. Ed. Rio de Janeiro: Paz e Terra, 1999.

FREIRE, P. Educação e mudança. 28ª ed. Rio de Janeiro: Editora Paz e Terra, 2005.

FUJITA, J. A. L. M; CARMONA, E. V; SHIMO, A. K. K; MECENA, E. H. Uso da metodologia da problematização com o Arco de Maguerez no ensino sobre brinquedo terapêutico. Revista Portuguesa de Educação, Braga, v. 29, n. 1, p. 229-258, jun. 2016. Disponível em <http://www.scielo.mec.pt/scielo.php?script=sci_arttext\&pid=S087191872016000100011\&lng=pt\&nrm=iso>. Acesso em: 19 de outubro 2018.

LIMA, V. V. Espiral construtivista: uma metodologia ativa de ensino-aprendizagem. Interface (Botucatu), Botucatu, v. 21, n. 61, p. 421-434, Jun. 2017. Disponível em: <http://www.scielo.br/scielo.php?script=sci_arttext\&pid=S1414-32832017000200421\&lng=en\&nrm=iso>. Acesso em: 20 de outubro de 2018.

LUZURIAGA, L. História da educação e da pedagogia. 12. ed. São Paulo: Nacional, 1980. Magne. - Porto Alegre: Artmed, 1999.

MELLO, C. C. B; ALVES, R. O; LEMOS, S. M. A. Metodologias de ensino e formação na área da saúde: revisão de literatura. Revista CEFAC, São Paulo, v. 16, n. 6, p. 2015-2028, Dez. 2014 . Disponível em < http://www.scielo.br/pdf/rcefac/v16n6/1982-0216-rcefac-16-06-02015.pdf> Acesso em 04 de agosto de 2018.

MESQUITA, S. K. C; MENESES, R. M. V; RAMOS, D. K. R. Metodologias ativas de ensino/aprendizagem: dificuldades de docentes de um curso de enfermagem. Revista Trabalho, educação e saúde, Rio de Janeiro, v. 14, n. 2, p. 473-486, Ago. 2016. Disponível em < http://www.scielo.br/pdf/tes/v14n2/1678-1007-tes-1981-7746sip00114.pdf>. Acesso em 24 de julho de 2018.

MITRE, S. M; SIQUEIRA-BATISTA, R; GIRARDI-DE-MENDONÇA, J. M; MORAIS-PINTO, N. M; MEIRELLES, C. A. B; PINTO-PORTO, C; MOREIRA, T; HOFFMANN, L. M. A. Metodologias ativas de ensino-aprendizagem na formação profissional em saúde: debates atuais. Ciência e Saúde Coletiva, Rio de Janeiro, v. 13, supl. 2, p. 2133-2144, dez. 2008. Disponível em: < http://www.scielo.br/pdf/csc/v13s2/v13s2a18.pdf>. Acesso em 19 de julho de 2018.

OLIVEIRA-BARRETO, A, C; GUEDES-GRANZOTTI, R. B; DOMENIS, D. R; PELLICANI, A. D; Métodos de avaliação discente em um curso de graduação baseado em metodologias ativas. Revista Ibero-Americana de Estudos em Educação, v. 12, n. 2, p. 1005-1019, 2017. Disponível em: <https://periodicos.fclar.unesp.br/iberoamericana/article/view/8745/6579. Acesso em 19 de julho de 2018. 
PERRENOUD, P. Avaliação: da excelência à regulação das aprendizagens - entre duas lógicas. São Paulo: Artmed, 1999.

PRADO, M. L; VELHO, M. B; ESPÍNDOLA, D.S; SOBRINHO, S. H; BACKES, V. M. S. Arco de Charles Maguerez: refletindo estratégias de metodologia ativa na formação de profissionais de saúde. Escola Anna Nery, Rio de Janeiro, v. 16, n. 1, p. 172-177, mar. 2012. Disponível em: $<$ http://www.scielo.br/scielo.php?script=sci_arttext\&pid=S1414-81452012000100023>. Acesso em: 19 de outubro de 2018.

QUEIROZ, C. T. A, P. e MOITA, F. M. G. S. C. Fundamentos sócio-filosóficos da educação: As tendências pedagógicas e seus pressupostos. Curso de Licenciatura em Geografia - EaD. Campina Grande; Natal: UEPB/UFRN, $\quad$ fasc. $\quad 15, \quad 2007.20$ Disponível $<$ http://www.ead.uepb.edu.br/ava/arquivos/cursos/geografia/fundamentos_socio_filosoficos_da_educacao/ Fasciculo_10.pdf $>$. Acesso em 15 de julho de 2018.

REUL, M. A; LIMA, E. D; IRINEU, K. N; LUCAS, R. S. C. C; COSTA, E. M. M. B; MADRUGA, R. C. R. Metodologias ativas de ensino aprendizagem na graduação em Odontologia e a contribuição da monitoria - relato de experiência. Revista da ABENO, v. 16, n. 2, p. 62-68, 2016. Disponível em: http://revodonto.bvsalud.org/scielo.php?script=sci_arttext\&pid=S1679-

59542016000200009\&lng=es\&nrm=iso\&tlng=pt. Acesso em: 16 de outubro de 2018.

ROMAN, C; ELLWANGER, J; BECKER, G. C; SILVEIRA, A. D; MACHADO, C. L. B; MANFROI, W. C. Metodologias ativas de ensino-aprendizagem no processo de ensino em saúde no Brasil: uma revisão narrativa. Clinical And Biomedical Research, Porto Alegre, v. 37, n.4, p. 349-357, 2017. Disponível em: <https://seer.ufrgs.br/index.php/hcpa/article/view/73911/pdf>. Acesso em: 17 de outubro de 2018.

ROTHER, E. T. Revisão sistemática X revisão narrativa. Acta Paulista de Enfermagem, São Paulo, v. 20, n. 2, p. 5-6, 2007. Disponível em: <http://www.scielo.br/pdf/ape/v20n2/a01v20n2.pdf>. Acesso em: 15 de outubro de 2018.

SANTOS, J. C. R; ROCHA, K. M; BARONEZA, A. M; FERNANDES, D. R; SOUZA, V. V; BARONEZA, J. E. Metodologias ativas e interdisciplinaridade na formação do nutricionista. Semina: Ciências Sociais e Humanas, Londrina, v. 38, n. 1, p. 117-128, jan./jun. 2017. Disponível em: <http://www.uel.br/revistas/uel/index.php/seminasoc/article/view/28205>. Acesso em: 18 de outubro de 2018.

SAVIANI, D. O legado educacional do "longo século XX" brasileiro. In: SAVIANI, Dermeval (et al.,). o legado educacional do século XX no Brasil. Campinas, SP: Autores Associados, 2004.

SILVA, J. L. L; ASSIS, D. L; GENTILE, A. C. A percepção de estudantes sobre a metodologia problematizadora: a mudança de um paradigma em relação ao processo ensino aprendizagem. Revista Eletrônica de Enfermagem, v.07, n. 01, p. 72-80, 2005. Disponível em: https://www.revistas.ufg.br/fen/article/view/852/1030. Acesso em: 16 de outubro de 2018.

SIMON, E; JEZINE, E; VASCONCELOS, E. M; RIBEIRO, K. S. Q. S. Metodologias ativas de ensino-aprendizagem e educação popular: encontros e desencontros no contexto da formação dos profissionais de saúde. Interface (Botucatu), Botucatu, v. 18, supl. 2, p. 1355-1364, $2014 . \quad$ Disponível em: <http://www.scielo.br/scielo.php?script=sci_arttext\&pid=S1414-32832014000601355\&lng=en\&nrm=iso>. Acesso em: 17 de outubro de 2018.

SOBRAL, F. R; CAMPOS, C. J. G. Utilização de metodologia ativa no ensino e assistência de enfermagem na produção nacional: revisão integrativa. Revista da Escola de Enfermagem da USP, vol. 46, n.1, 208-18, 2012. Disponível em <http://www.scielo.br/pdf/reeusp/v46n1/v46n1a28.pdf $>$. Acesso em 07 de agosto de 2018.

TREVISO, P; COSTA, B. E. P. Percepção de profissionais da área da saúde sobre a formação em sua atividade docente. Texto contexto - Enfermagem, Florianópolis, v. 26, n. 1, e 5020015, 2017. Disponível em $<$ http://www.scielo.br/pdf/tce/v26n1/pt_0104-0707-tce-26-01-e5020015.pdf>. Acesso em 20 de julho de 2018. 
VENDRUSCOLO, C; SILVA, M. T; SILVA, M. E K. Integração ensino-serviço-comunidade na perspectiva da reorientação da formação em saúde. Revista Sustinere, Rio de Janeiro, v.5, n. 2, p. 245-259, jul-dez 2017. Disponível em: <http://www.e-publicacoes.uerj.br/index.php/sustinere/article/view/30559>. Acesso em: 16 de outubro de 2018.

VIEIRA, M. A; SOUTO, L. E. S; SOUZA, S. M; LIMA, C. A; OHARA, C. V. S; DOMENICO, E. B. L. Diretrizes Curriculares Nacionais para a área de enfermagem: o papel das competências na formação do enfermeiro. Revista Norte Mineira de Enfermagem, v. 5, n. 1, p. 105-121, 2016. Disponível em: <http://www.renome.unimontes.br/index.php/renome/article/view/102/148>. Acesso em: 17 de outubro de 2018.

\section{(c) EY}

Este trabalho está licenciado com uma Licença Creative Commons - Atribuição 4.0 Internacional. 